\title{
LAS DISPOSICIONES ATÍPICAS DEL TESTAMENTO Y SU EJECUCIÓN EN CUBA. ESPECIAL REFERENCIA A LA UTILIDAD PRÁCTICA DEL ALBACEA
}

The atypical dispositions of the will and its execution in Cuba. Special reference to the practical utility of the executor

OSMAIDY LeGRÁ GaÍNZA* UNIVERSIDAD DE ORIENTE SANTIAGO DE CUBA, CUBA

\footnotetext{
* Profesora auxiliar de Derecho Civil y Familia de la Universidad de Oriente, Santiago de Cuba, Cuba. Abogada. Correo electrónico: <olegra@uo.edu.cu>.
}

Artículo recibido el 24 de enero de 2018 y aceptado para publicación el 16 de marzo de 2018. 
RESUMEN: El panorama de la ejecución del testamento, en cuanto a la utilización de la figura del albacea para dar cumplimiento a las disposiciones típicas o patrimoniales en Cuba, no es enriquecedor, pues la legislación civil cubana y la práctica jurídica así lo evidencian. Particularmente, la ejecución de las disposiciones atípicas presenta una problemática que parte de la concepción patrimonialista del contenido testamentario en nuestro país. De ahí que los preceptos acogidos en el capítulo IV, del Libro Cuarto del Código Civil cubano en sus artículos 505 al 508, relativos al albaceazgo, sean reflejo de la citada noción del testamento. En razón de ello pretendemos realizar algunas valoraciones sobre el tema desde el análisis del contenido del testamento como acto jurídico hasta el de algunas disposiciones atípicas y su ejecución.

Palabras Clave: testamento, disposiciones no patrimoniales, ejecución.

ABSTRACT: The panorama of the execution of the will, regarding the use of the executor's figure to comply with the typical or patrimonial dispositions in Cuba, it is not enriching, since the Cuban civil legislation and legal practice evidences. Particularly, the implementation of the atypical provisions presents a problem that starts in the patrimonialist conception of the testamentary content in our country. Hence, the precepts received in chapter IV of the fourth book of the Cuban Civil Code in articles 505 to 508 relating to the albaceazgo, are a reflection of the aforementioned notion of the will. Consequently we intend to make some evaluations on the subject starting from the contents of the will as a legal act until the analysis of some atypical dispositions and their execution.

KEYWORDS: will, non-equity provisions, execution. 


\section{INTRODUCCIÓN}

Aparejado a los cambios socioeconómicos acaecidos en Cuba a partir de la llegada del Periodo Especial hasta la actualidad, la dinámica familiar se ha impregnado de matices significativos. En el ámbito socio-jurídico han aumentado considerablemente los actos jurídicos testamentarios, siendo notoria la pluralidad de manifestaciones de la voluntad que se trasmiten hoy en sede notarial por parte de los usuarios, que van desde la voluntad de disponer, a título universal o particular, de determinados bienes, hasta disposiciones desprovistas de un carácter patrimonial que responden a los avances del país, en el plano socioeconómico, científico y cultural, como la posibilidad de la fecundación asistida y de la incineración de cadáveres. Todo ello indica que la figura del albacea irremediablemente deberá tomar preeminencia pues, como ha sido evidente en los últimos años, la autonomía de la voluntad de los testadores se desplaza ya no sólo al plano patrimonial, erigiéndose así disposiciones atípicas que tienen particularidades, en las cuales no siempre el testador confía para su ejecución a los herederos. Son disposiciones que responden a las más variadas subjetividades del testador siendo, en muchos casos, contrarias a los intereses de los sucesores, ya sea por desfavorecerlos en el plano patrimonial, como por colisionar con principios éticos, morales y religiosos.

No podemos decir que la figura del albacea para dar cumplimiento a las disposiciones típicas o patrimoniales en la legislación civil cubana goce de gran esplendor, la práctica jurídica así lo evidencia. Particularmente en relación a la ejecución de las disposiciones extra-patrimoniales, la cuestión se torna más problemática partiendo de la concepción patrimonialista del testamento en nuestro Código Civil. En consecuencia, con lo referido anteriormente pretendemos realizar algunas valoraciones sobre el tema partiendo del análisis del contenido del testamento como acto jurídico, hasta el análisis de algunas disposiciones atípicas y los dilemas que se pueden suscitar respecto a su ejecución en el ordenamiento jurídico cubano. 


\section{LA DEFICIENTE CONCEPTUALIZACIÓN DEL TESTAMENTO}

El contenido extra-patrimonial del testamento se ha presentado como un tema relevante a la luz del Derecho de Sucesiones y el Derecho de Familia Contemporáneo, pues, indudablemente, pretender que el testamento deba contener esencialmente carácter patrimonial sería menoscabar la facultad o capacidad de testar a las personas carentes de bienes o tanto como admitir que el ejercicio de la cualidades inherentes a la persona o los privilegios primordiales al individuo están en dependencia de si tengan o no patrimonio. Se han establecido serios debates en torno a la posible admisión o no de que el testamento pueda albergar disposiciones no patrimoniales, sin embargo, el verdadero centro de atención hoy pudiera estar dirigido hacia los criterios que consideran estas disposiciones extra-patrimoniales como contenido único de un testamento, prescindiéndose de la disposición de bienes. El estudio del tema en Cuba ha sido muy incipiente, $y$ aunque debatido en diversos espacios jurídicos, resulta aún novedoso en tanto no existe en la actualidad regulación alguna que indique la posible admisión de estas disposiciones.

La problemática parte de la definición de testamento que tanto en la doctrina como en las legislaciones se han esgrimido, lo que ha constituido una labor emprendida por muchos tratadistas y estudiosos del Derecho. No han sido pocos los autores que han emitido sus consideraciones al respecto, lo que demuestra no sólo lo controvertido de esta tarea, sino también la diversidad de criterios que, en torno a este particular, se sostienen. Contundentes señalamientos han surgido respecto a las definiciones proporcionadas de testamento, aunque la paradoja parezca inverosímil si se tiene en cuenta el desarrollo histórico por el que ha atravesado la institución, pero alerta con relación a las consecuencias que pueden derivarse de una incorrecta o incompleta conceptualización.

Como se expondrá, con generalidad ha sido definido el testamento en la doctrina como "el acto jurídico por el cual una persona dispone de todo o parte de sus bienes para después de su muerte". En este sentido, muy seguida es la crítica del tratadista SÁnCHEZ RoMÁn, a la que nos adherimos, referente a la definición antes expuesta. Plantea, en primer lugar, que dicha definición no es exacta, en cuanto hace del testamento algo equivalente tan solo a una fórmula jurídica de ejercicio del poder de libre disposición 
de bienes, atribuyéndole un sentido exclusivamente patrimonial. Además, refiere que no es completa, en virtud de no contener los caracteres esenciales del testamento (ser un acto personalísimo, solemne, revocable, etc.), de los cuales depende su validez y eficacia. Por último la considera poco útil, planteando que de ésta no resulta aplicación práctica alguna'.

En tal sentido, el propio SÁNCHEZ Román ha concebido el testamento como un acto jurídico mortis causa, personalísimo, singularmente individual y unilateral, otorgado por una persona con la capacidad especial legalmente necesaria, y con sujeción estricta a las formas de la ley, esencialmente revocable hasta su muerte, por virtud del cual declara su última voluntad acerca de la disposición de todos o parte de sus bienes, derechos y obligaciones trasmisibles, y de cuantas otras manifestaciones de aquella se establezcan en el mismo, aunque no tengan aplicación patrimonial ${ }^{2}$. Desdeñar tal afirmación sería hurgar sobre lo incompleto e insuficiente. Es un concepto muy acabado en cuanto brinda una pormenorizada idea del instituto, acogiendo no sólo sus más peculiares caracteres, sino dando el más amplio alcance a su contenido.

Autores como Rıccı también han conceptualizado al testamento, entendiéndolo como la facultad concedida al individuo de disponer de sus bienes para después de su muerte ${ }^{3}$. Es en esencia, una definición incompleta y estéril que omite las características del testamento y limita su contenido a lo meramente patrimonial, limitando la voluntad individual a la disposición de bienes.

GorenA ${ }^{4}$ define al testamento como la disposición en que manifiesta el otorgante su última voluntad, principalmente respecto de sus bienes y derechos para que se cumpla después de su muerte. A nuestro entender es también un concepto incompleto y defectuoso pues, en primer lugar, no da una idea cierta de los caracteres del testamento y, en segundo lugar, sólo es extensiva a los bienes y derechos del testador.

1 A decir del autor, "no sería reprochable que las definiciones legales comprendieran todos los elementos esenciales y característicos de cada institución". Vid. SánCHEZ, cit. pos. RIVAS (2005), p. 79 .

2 SÁNCHEZ (1910) p. 207.

3 RiCCI (1925) p. 228.

4 Goyena, cit. pos. López (1916), p. 49. 
Por su parte, FALCóN ${ }^{5}$ brinda una definición muy distinta de la anterior, al considerar el testamento como una manifestación solemne de la última voluntad del hombre, en la cual decide sobre los asuntos más importantes de la familia y dispone de los bienes para después de la vida. Ciertamente, el autor expresa una de las características del testamento, el carácter solemne de éste, sin embargo, omite las demás. Por otro lado, suscribe la facultad de disposición a los bienes y a los derechos de familia, excluyendo los deberes que el hombre puede cumplir por medio de este instrumento.

Morató ${ }^{6}$, sustentado en las definiciones romanas de testamento, lo considera como la solemne manifestación de nuestra voluntad acerca de lo que queremos que se haga después de nuestra muerte. Es una definición concebida en términos bien generales pero, indiscutiblemente, es una de las más acertadas teniendo en cuenta que si bien omite los caracteres del testamento, no restringe el objeto de las disposiciones testamentarias.

Según el tratadista López R. GómEZ7, el testamento es un acto personalísimo, solemne, revocable y libre, por el cual una persona capaz dispone de sus bienes y derechos y declara o cumple deberes para después de la muerte. De igual forma, esta definición reduce la libertad de disposición, aun estipulando sus variados caracteres.

VALVERDE Y VALVERDE lo definen como un negocio jurídico de disposición mortis causa, unilateral y autónomo, el cual no confiere ningún derecho actual al beneficiario o sucesor del causante y por el que el otorgante trasmite sus derechos y obligaciones a otra persona para después de su muerte. Para este autor, definir al testamento como un "acto meramente dispositivo de bienes" resulta "un concepto estrecho de testamento", en virtud de considerar que otras declaraciones que afectan a la conciencia y al deber moral pueden formar parte de éste ${ }^{8}$.

Pérez Gallardo ${ }^{9}$, acertadamente, concibe al testamento como la expresión de la última y deliberada voluntad de un ser humano, exteriorizada

5 FALCón, cit. pos. LóPez (1916) p. 49.

6 Morató, cit. pos. López (1916) p. 50.

7 LÓPEZ (1916) p. 50.

8 VAlVerde (1939) pp. 52-55.

9 PÉREZ (2004) p. 211. 
solemnemente, conforme con la ley, por persona capaz para que surta efectos jurídicos frente a terceros sólo después de la muerte de su otorgante, sin necesidad de que llegue a su conocimiento, por el cual se ordena la sucesión mortis causa de su autor, pudiendo ser reservorio de otras manifestaciones de voluntad de carácter no patrimonial.

A nuestro entender, es evidentemente el testamento como un negocio jurídico unilateral, personalísimo y solemne, esencialmente revocable, en virtud del cual una persona física con capacidad suficiente, según su arbitrio y las normas legales, dicta disposiciones, ya sean patrimoniales o no, para surtir efectos después de su muerte. Consideramos de especial importancia los defectos que le atribuimos a las definiciones de testamento ofrecidas doctrinalmente, y en consecuencia su formulación impone la necesidad de hacerse sobre una base de mayor rigor científico y eficacia práctica. Si bien los rasgos y caracteres del testamento pudieran enunciarse al establecer un concepto de éste, buscando una verdadera aproximación al instituto, derivamos también trascendental el reflejo en su conceptualización del carácter extensivo de las disposiciones que forman el contenido testamentario.

\section{EL CONTENIDO DE LAS DISPOSICIONES JURÍDICAS TESTAMENTARIAS}

El cumplimiento de los deberes del hombre, atendida su naturaleza, es la causa determinante del ejercicio del mismo derecho de testamentifacción, que manifestándose en la voluntad de aquél ordena lo concerniente a los bienes y derechos que le pertenecen con el carácter de trasmisibles; ejercita derechos personalísimos e intrasmisibles a terceros y que sólo pueden ser efectivos por medio del testamento, declara o cumple deberes que pueden ser también objeto de otras formas de libre elección concedida por la ley, y establece manifestaciones de carácter no patrimonial.

En todo testamento, el testador expresa su última voluntad, por lo que pretender reducir el contenido del testamento a un patrón o estándar es en realidad inútil, porque su contenido es todo aquello que el autor quiera ordenar, $y$, como las voluntades son muy diversas, un testamento podrá contener disposiciones muy variadas también. 
La disposición de los bienes y derechos es considerada, por algunos autores y tratadistas, como el contenido típico del testamento, estableciendo la nota de patrimonialidad, con la cual ha sido caracterizado, en relación al objeto de disposición, el patrimonio, entendido éste, a decir de CASTÁN TobeÑas, como "el conjunto de derechos, susceptible de estimación pecuniaria, íntimamente ligados entre sí por su afectación a los fines generales de una persona como centro de su poder jurídico o por su afectación a un destino especial y a los que la ley, en algunos casos, otorga la consideración de una unidad abstracta (universitas iuris) de la que forman parte también las obligaciones del titular"10.

El llamado contenido típico y "principal", en cuanto a disposición de bienes y derechos, se puede hacer por dos vías: a título universal: institución de heredero y a título particular: el legado.

La disposición a título universal implica dejar a una persona la totalidad o una fracción del patrimonio del testador-causante. Al dejársele esta totalidad o parte del patrimonio, la persona a quien se le deja sucede en la totalidad de estos bienes y derechos como si continuase la relación que con ellos tenía el difunto.

Quien es nombrado heredero sucede, colocándose en el lugar del difunto, en la totalidad o parte de su patrimonio y no sólo en la parte activa sino también haciéndose cargo del pasivo: deudas del difunto, viniendo a decirse que el heredero continúa la personalidad del difunto.

Por el contrario, en la disposición a título particular, cuya principal figura es el legado, se sucede únicamente en el bien o derecho concreto, de tal forma que el que lo adquiere no se ve obligado a responder de las deudas del difunto con su propio patrimonio sino de las deudas que conllevare el legado que recibe, de proceder.

Si la institución de herederos y el nombramiento de legatarios ha sido considerado el contenido típico principal, doctrinalmente se ha hecho referencia a otro contenido típico de carácter instrumental, teniendo como exponentes principales el nombramiento de albacea y el de contador-partidor, personas que, desde su ámbito, se encargan de velar por

10 CASTÁN (1952) p. 423. 
el cumplimiento del testamento y el reparto del patrimonio. No obstante, somos del criterio que, si bien el nombramiento de albaceas ha estado asociado a la ejecución patrimonial del testamento, la naturaleza de esta disposición es de índole extra-patrimonial, dado que es sólo un llamamiento específico a determinada persona para que a la muerte del testador ejecute la voluntad de éste. Ahora bien, puede que dicha voluntad esté referida al reparto del patrimonio del causante, empero pudiera estar desprovista de carácter patrimonial. Entonces no habría razón para clasificarla con dependencia del objeto de la disposición, pues las facultades del albacea en si sólo quedan limitadas por el testador y no necesariamente encaminadas con absolutismo a la ejecución de las disposiciones de carácter patrimonial.

Tal como se ha venido expresando, el testamento puede contener otra serie de disposiciones no dirigidas a regir el destino y reparto de la herencia, que se consideran atípicas o extrañas a la sucesión. Según Pérez GALLARDO ${ }^{11}$ es contenido atípico del testamento aquel conjunto de disposiciones suficientemente numerosas, frecuentes y representativas de los diversos actos jurídicos que pueden formar parte de un testamento por disposición legal o por decisión propia del testador.

Así, VAlVerde y VALVerde ${ }^{12}$ plantean que el contenido de los testamentos lo forman todas aquellas disposiciones que el testador puede ordenar, tanto en relación con los derechos que a su muerte han de ser trasmitidos como lo que se refiere al cumplimiento de deberes que han de ser realizados o consumados después de su fallecimiento, así como disposiciones de índole familiar o cuasi familiar.

Autores como KIPP13 han clasificado las disposiciones testamentarias agrupándolas bajo diversos rubros. Establece una primera clasificación referida al destino del patrimonio, distinguiendo entre "disposiciones por las que se regula materialmente la permanencia del patrimonio" y "disposiciones por las que se establece lo pertinente para la realización de cuanto ha dejado dispuesto el causante en orden a la permanencia de su

11 PéREZ (2004) p. 234.

12 VAlVerde (1939) p. 159.

13 Vid. ENNECCRUS et. al. (1951) pp. 66-68. 
patrimonio". Por su parte, el propio autor admite la existencia de disposiciones cuya explicación detallada corresponde al Derecho de Familia.

Desde otra óptica, JORDANO ${ }^{14}$ ha clasificado el contenido del testamento estableciendo diferencias entre las declaraciones normales y típicas, y las declaraciones anómalas testamentarias, patrimoniales o no patrimoniales, de índole negocial, ya sean típicas o atípicas.

Al tratar las normales o típicas hace alusión dentro de éstas a las que él Ilama principales (institución de herederos, legados y carga modal) y a las accesorias e instrumentales (las disposiciones sobre la administración de los bienes legados a menores, el testamento revocatorio de otro anterior, las disposiciones encomendando al arbitrio de tercero decisiones que permite la ley en tema de distribución de la herencia, la fijación del orden de pago de los legados, el nombramiento de albaceas, la delimitación de sus facultades, disposiciones sobre la colación o partición, etc.).

Respecto a las declaraciones anómalas testamentarias patrimoniales o no, hace distinción entre las típicas (previstas por la ley, como la rehabilitación del indigno, las disposiciones sobre sufragios y funerales, las disposiciones sobre el propio cadáver) ${ }^{15}$. Para el caso de las atípicas (no previstas por la ley), pone de ejemplo las disposiciones sobre la suerte de la correspondencia, sobre el derecho de autor, la designación testamentaria del tercero beneficiario del contrato de seguro de vida, entre otras) ${ }^{16}$.

14 Jordano Barea, cit. pos. Lacruz y Binder (1953) p. 220.

15 Las anómalas serán clasificadas de típicas en correspondencia de si son previstas o no en determinado ordenamiento jurídico. El autor $v$. gr. se refiere a las disposiciones sobre el cadáver como típica porque es regulada en el ordenamiento que toma como punto de análisis.

En materia de contenido testamentario resulta además interesante lo planteado por el tratadista SÁNCHEZ Román, quien ha proseguido la postura de que el testamento, no obstante de ser un acto jurídico, su contenido no siempre es jurídico, es decir que resultará jurídico en cuanto a la forma de la especie jurídica testamentaria, pero no es forzoso que lo sea en el fondo de todas sus disposiciones o declaraciones de aquella última voluntad. El autor establece una distinción entre aquellas disposiciones que pueden formar parte del contenido testamentario y en este orden se refiere a las que son de aplicación directa al patrimonio, referidas a los actos en que directamente se dispone de los bienes en el testamento; a otras con aplicaciones indirectas al mismo, entre las que ejemplifica los actos de reconocimiento de hijo natural, y por último hace referencia a algunas que no son de aplicación, como las protestas de fe religiosa, de conducta y otras semejantes. Vid. SÁNCHEZ (1910), p. 207. 
En armonía con lo planteado por los autores tratados, efectivamente el contenido del acto jurídico testamentario es todo aquello que ineludiblemente el testador pueda consignar en las disposiciones que lo conforman. Desde luego, éstas en sí pueden albergar un contenido muy variado tanto de carácter patrimonial como extra-patrimonial, sin embargo, creemos que las clasificaciones ofrecidas doctrinalmente en cierto sentido crean diferencias en cuanto a la relevancia de unas y otras disposiciones testamentarias. Así hacen alusión a las de carácter extra-patrimonial como anómalas, no principales o extrañas, cuando son tan principales y normales como las referidas al patrimonio del causante.

Denominándolas disposiciones anómalas (típicas o atípicas) o correspondientes al Derecho de Familia, lo cierto es que a priori puede inferirse que la doctrina en materia sucesoria ha reconocido dentro del contenido testamentario las disposiciones de carácter no patrimonial previstas o no en la ley, aun cuando no ha sido consignado con absolutismo tal alcance en las definiciones de testamento que, doctrinalmente, se exponen.

\section{El contenido extra-patrimonial de las disposiciones testamentarias}

Cuando analizábamos el concepto de testamento, que con generalidad ha sido difundido en la doctrina de la mayoría de los países ${ }^{17}$, nos referíamos a éste como un acto jurídico dispositivo de bienes, derechos y obligaciones. Indudablemente una de las críticas esenciales a tal definición se ha centrado en su alcance limitado respecto al contenido extra-patrimonial de las disposiciones testamentarias. No puede verse al testamento sólo como un acto dispositivo de bienes, pues puede contener

17 Art. 667 del Código Civil de España: "El acto por el cual una persona dispone para después de su muerte de todos sus bienes o de parte de ellos, se llama testamento"; artículo 686 del Código Civil de Perú: "Por el testamento una persona puede disponer de sus bienes, total o parcialmente, para después de su muerte, y ordenar su propia sucesión dentro de los límites de la ley y con las formalidades que ésta señala. Son válidas las disposiciones de carácter no patrimonial contenidas en el testamento, aunque el acto se limite a ellas". 
además otras disposiciones de carácter personal y familiar, por lo que se ha impregnado el criterio erróneo de considerar su contenido como normalmente patrimonial ${ }^{18}$.

Sin embargo, el reconocimiento y admisión de estas disposiciones sin contenido patrimonial en la doctrina moderna ya casi no resulta un tema discrepante. La coexistencia de las disposiciones no patrimoniales junto a las de carácter patrimonial son bien entendidas y admitidas en el derecho moderno. La polémica surge a tenor de considerar estas disposiciones accesorias a las patrimoniales, o si por el contrario pudieran formar parte única del contenido testamentario.

Las disposiciones testamentarias no patrimoniales pudiéramos definirlas como aquellas manifestaciones de la voluntad de una persona, con eficacia post mortem, relativas a cuestiones no susceptibles de evaluación pecuniaria o que no suponen disposición de bienes, y que en determinados casos afectan el Derecho de Familia. Éstas deben ser cumplidas, cuando ello sea posible, por los sucesores y albaceas. Y son también manifestaciones del principio de autonomía de la voluntad del testador.

La extra-patrimonialidad del testamento ha sido superada, como definición del mismo al menos en un sentido formal, por casi la totalidad de la doctrina. La inclusión en el testamento de disposiciones denominadas anómalas o atípicas, entre las que se encuentran disposiciones de carácter no patrimonial, es innegable. Sin embargo, desde una perspectiva sustancial siguen manteniéndose posiciones diversas. No pocos autores mantienen el criterio de considerar al testamento como un acto jurídico mortis causa con un amplio y variado contenido ${ }^{19}$.

18 El Tribunal Supremo de España en la Sentencia de 22 de diciembre de 1964, antes de la reforma de 1981 al Código Civil español, había admitido validez y eficacia a un testamento que sólo contenía el reconocimiento de un hijo extramatrimonial, sin hacerse disposición alguna de bienes, ni de ninguna otra mortis causa. Esta sentencia rechazó un recurso que pretendía que el citado testamento no era verdaderamente tal por no contener disposición de bienes para después de la muerte y limitarse sólo al reconocimiento de un hijo. El Tribunal Supremo, en ponencia del Magistrado VICENTE TUTOR, declaró: “...como quiera que la jurisprudencia viene reconociendo como testamento aquellos en que expresada la voluntad del testador se determine el reconocimiento de un hijo natural, o el nombramiento de tutor, etc., aparece evidente que el de referencia debe calificarse como tal con toda la fuerza que le concede el art. 741 del Código y no puede prosperar el recurso". Rıvas (2005), p. 89.

19 En la doctrina italiana se distingue entre testamento formal que sería todo acto que reviste las formalidades legales, haya o no disposiciones de bienes, y testamento sustancial que requiere la disposición de bienes. BOrDA (1994) p. 1120. 
Así, Planiol y Ripert han expresado que "Ios legados y las cargas patrimoniales constituyen las principales disposiciones testamentarias, pero frecuentemente el testamento contiene disposiciones puramente extra-patrimoniales, previstas o no por la ley. Más aun, un testamento puede limitarse a disposiciones extra-patrimoniales, sin contener legado alguno" ${ }^{\prime 20}$. El autor reconoce y considera válido el testamento que sólo contenga disposiciones no patrimoniales, sin embargo considera que las patrimoniales son su contenido esencial, lo que pudiera resultar contradictorio, porque si es admitida la validez de una disposición extra-patrimonial como único contenido de un testamento, sería incongruente sostener que las disposiciones de contenido patrimonial son principales porque de esta forma nos da la idea de que se ha pretendido jerarquizar ambos tipos de disposiciones, patrimoniales y no patrimoniales, cuando en realidad se reconoce que pueden constituir independientemente el contenido de un testamento.

En ese mismo sentido SÁNCHEZ ROMÁN ${ }^{21}$ ha planteado que aun cuando el carácter patrimonial del testamento sea el más visible y virtual de su aplicación, no es el único. Refiere además que el testamento lo mismo puede comprender sirviendo tanto a las complejas necesidades de la vida civil, mediante disposiciones acerca de los bienes, como con declaraciones y derechos relativos a las personas. Lo mismo respecto de las relaciones patrimoniales, que ético-jurídicas tales como cláusulas de fines piadosos, de caridad o de instrucción, de revelación de responsabilidades morales o secretas de carácter personal, de reglas de conducta, consejo o admoniciones a otras personas y de otorgamiento de promesas para la realización de ciertos actos. Una cosa es considerar que en la práctica jurídica lo más visible sean los testamentos con contenido patrimonial y otra es plantear que las disposiciones de carácter patrimonial son principales respecto a otras de contenido no patrimonial.

Por su parte, LACRUz BeRDejO ${ }^{22}$ sostiene que no hay inconveniente en admitir que las disposiciones no patrimoniales puedan ser establecidas en la forma prevenida para los testamentos, y ello independientemente de si el instrumento contiene o no disposiciones patrimoniales, estableciendo como argumento que cuando la ley permite otorgar aquellas

20 Planiol Y Ripert (1935) P. 661.

21 SÁNCHEZ (1910) p. 207.

22 LACRUZ Y BINDER (1953) p. 123. 
en testamento, y a veces veda hacerlo en otros tipos de negocio, lo que requiere es la forma testamentaria y no la disposición de bienes. Coincidimos con este autor además en el sentido de lo injusto, que sería subordinar la validez de las disposiciones no patrimoniales a la existencia de un pequeño legado.

El propio autor refiere que la dificultad que podría oponerse a un negocio de esta clase, como "esencialmente un acto dispositivo de bienes o derechos", no se dirige tanto contra la validez del instrumento que contiene exclusivamente disposiciones no patrimoniales para después de la muerte, como contra su calificación como testamento en sentido material. En ese sentido afirma que con este alcance la objeción es aceptable, porque dado un instrumento de ese tipo, la apertura de la sucesión intestada procede.

Otros autores en la doctrina ${ }^{23}$, no siendo el sector mayoritario, tienen una concepción restringida y estricta del testamento al considerarlo desde una perspectiva sustancial, un negocio jurídico de atribución patrimonial a causa de muerte. Dentro de estos autores se encuentra RotonDI, quien considera que no es necesario que el testamento contenga institución de heredero, es decir el llamamiento de una o varias personas a la universalidad del patrimonio, o puede ocurrir que el testamento no contenga más que una o varias disposiciones a título particular, pero refiere que lo indispensable es que a lo menos existan disposiciones de contenido patrimonial ${ }^{24}$.

23 CASTÁN (1989) pp. 464-465.

24 Rotondi (1953) p. 616. 


\section{Clases de disposiciones testamentarias extra-patrimoniales}

Una vez entendidas las diversas posturas respecto al contenido del testamento en orden a su carácter patrimonial y extra-patrimonial, así como planteada la afirmación positiva en torno a la validez de las disposiciones extra-patrimoniales como único contenido del testamento, nos resulta oportuno referirnos a dos categorías de disposiciones extra-patrimoniales planteadas en la doctrina. A decir de PLANIOl y RIPERT ${ }^{25}$, éstas pueden distinguirse de la siguiente forma:

i. Disposiciones extra-patrimoniales, que se traducen en simples consejos morales o directrices para la vida, dirigidas a aquellas personas que el testador deja a su muerte, y que carecen de importancia jurídica, salvo que constituyan la condición de alguna disposición patrimonial.

ii. Disposiciones extra-patrimoniales, que por el contrario están previstas y sancionadas por la ley.

Dentro de la gran gama de disposiciones de carácter no patrimonial que pueden formar parte de un testamento existen algunas que por su naturaleza no tienen trascendencia al ámbito jurídico. Si bien constituyen manifestaciones de la voluntad del testador, en la mayoría de los casos no poseen un carácter imperativo y por tanto se traducen en simples expresiones de su autor que pueden ser acatadas o admitidas por determinadas personas a las que van dirigidas, no siendo en sí de obligatoria ejecución. Sin embargo, existe un gran número de disposiciones no patrimoniales que denotan una marcada trascendencia al ámbito jurídico y que doctrinalmente han sido veneradas por diversos tratadistas.

Entre estas declaraciones testamentarias no patrimoniales previstas por los ordenamientos jurídicos se pueden citar las que siguen:

a) El consentimiento para la fecundación post mortem, esto es la posibilidad de que la fecundación se produzca tras la muerte del padre donante del material reproductor y sobre la base de un consentimiento por él emitido; uno de los cauces posibles para la emisión de tal consentimiento es, precisamente, el testamento.

25 Planiol y Ripert (1935) p. 661. 
b) La designación del beneficiario del seguro de vida, esto prevé la posibilidad de que el tomador del seguro de vida designe al beneficiario en su testamento, asimismo cabe esta designación en la propia póliza o en una declaración escrita comunicada al asegurador. La designación del beneficiario puede ser, por lo tanto, testamentaria y se puede realizar en esta forma, lo cual no significa que nos hallemos ante un acto mortis causa sino que conserva su naturaleza inter vivos y, más concretamente, la de estipulación a favor de tercero, eso sí, con eficacia post mortem. En definitiva, la designación del beneficiario en testamento no desnaturaliza su posición jurídica, sino que éste sigue ajeno a la herencia, el estipulante, a pesar de utilizar la forma testamentaria, no realiza ninguna atribución sucesoria específica. Sustentar tal tesis conlleva importantes consecuencias, amén de la propia configuración jurídica del negocio.

c) Reconocimiento de deudas, advirtiéndose aquí la posibilidad para que el testador, en testamento, efectúe disposiciones en las que reconozca ciertas deudas o derechos en favor de otras personas. Serían, en este caso, disposiciones confesorias cuya admisibilidad jurídica no se cuestiona doctrinalmente.

d) La designación de las personas que hayan de ejercitar ciertas acciones relativas a la protección del honor, la intimidad y propia imagen de la persona fallecida y a la divulgación, paternidad e integridad de la obra. Doctrinalmente se ha señalado la posibilidad de que el testador nombre en su testamento a la persona que promueva, en su caso, el ejercicio de las acciones de protección civil del honor, la intimidad o imagen de la persona fallecida, nombramiento que puede recaer, asimismo, en una persona jurídica. Además, se ha debatido la posibilidad de que el testador pueda nombrar, en testamento, a la persona natural o jurídica que, a su fallecimiento, ejercite los derechos relativos a la decisión sobre la divulgación de la obra y su forma, exija el reconocimiento de su condición de autor de la obra y el respeto a la integridad de la misma e impida cualquier deformación, modificación, alteración o atentado contra ella que suponga perjuicio a sus legítimos intereses o menoscabo a su reputación.

e) La constitución de una fundación. Se configuraría así el negocio jurídico fundacional como un negocio sui generis destinado a crear una 
persona jurídica mediante la adscripción de un conjunto de bienes a un fin de interés general. Ello significa que aunque se realice en un testamento no existen dos negocios, el fundacional y el de dotación, sino uno sólo. Así la dotación en la fundación creada mortis causa no se califica como herencia o legado a favor de la fundación creada en el testamento, $y$, consiguientemente, la disposición testamentaria en este sentido formaría parte de lo que calificamos, y por ello su tratamiento en esta sede, del contenido atípico o de las disposiciones anómalas testamentarias. Incluso se ha rechazado la configuración de negocio jurídico mortis causa para calificar la fundación testamentaria; más bien se trataría de un negocio post mortem: la eficacia del negocio se defiere hasta la muerte del testador, pero no halla en ella su causa.

f) Disposiciones sobre el destino del cadáver. Se prevé la posibilidad de que por medio del testamento se declare la voluntad del testador en relación al destino de su cadáver.

g) El reconocimiento de hijos. Mediante la vía testamentaria se declara la maternidad o paternidad de un hijo menor o mayor de edad no reconocido al nacer. Es un tipo de reconocimiento voluntario.

h) La designación de tutor. Es la designación testamentaria de una o varias personas hecha por el padre, la madre o por terceras personas ajenas a los padres, pero no excluyendo la designación de éstos para que a su muerte brinden protección y cuidado a sus hijos menores o incapaces.

$\mathrm{Al}$ admitir y reconocer que las disposiciones atípicas del testamento pueden formar parte de su contenido e incluso tener plena validez prescindiendo de la disposición de bienes, considerándolas también testamento en sentido material, se conduciría ineludiblemente a la aplicación de los caracteres definidores del testamento y sus requisitos (la revocabilidad, eficacia mortis causa, requisitos de capacidad del testador, vicios del consentimiento, etc.). Si por el contrario se estima que el testamento no es más que un vehículo formal de incorporación de tales disposiciones, a éstas se le aplicaría un régimen jurídico perteneciente a su naturaleza jurídica, vinculándose sólo a las exigencias de forma del testamento.

Desde el punto de vista doctrinal no ha habido consenso al plantear las disyuntivas antes mencionadas, porque en algunos casos suele ser muy 
fácil razonar que la forma testamentaria llena el requisito formal del acto. Sin embargo, en diversas ocasiones es evidente la intención del declarante de dotar al acto de validez para después de la muerte y no sólo cubrir las exigencias formales. Por tanto, lo más acertado es establecer los anteriores análisis a cada una de las disposiciones no patrimoniales, de forma independiente, penetrando en sus peculiaridades.

\section{LA EJECUCIÓN DE LAS DISPOSICIONES TESTAMENTARIAS: EL ALBACEAZGO EN CUBA}

El llamado por el testador a ejecutar las disposiciones del testamento se denomina albacea. Sin embargo, el albaceazgo ha sido en la práctica fuente de diversos conflictos con los herederos. Y esto ocurre porque, conforme al sistema romanista de la successio in locum et ius $\mathrm{O}$, si se prefiere, de la "continuación" de la persona del causante por el heredero que informa el derecho moderno de tradición romanista, la administración de la herencia, a partir de la propiedad y la posesión de los bienes relictos y, consiguientemente, la ejecución de las disposiciones del testador, compete a los propios herederos.

Los albaceas son personas designadas por el testador para hacer cumplir sus disposiciones de última voluntad. Por ello se los llama también ejecutores testamentarios. Ocurre con frecuencia que los herederos del causante, cuyos intereses son contrapuestos a los de los legatarios o beneficiarios de los cargos, suelen no cumplir estas disposiciones, o lo hacen de mala gana, reduciendo su alcance o demorando su pago. La experiencia ha demostrado que es conveniente que alguien de la confianza del causante haga cumplir sin dilaciones ni retaceos su última voluntad. Otras veces la intervención del albacea es un arbitrio destinado a evitar cuestiones entre coherederos mal avenidos. Finalmente, puede ocurrir que no haya herederos, en cuyo caso el ejecutor testamentario es casi indispensable para proceder a la liquidación de los bienes, tramitar el sucesorio, pagar deudas, legados y ejecutar o vigilar las disposiciones testamentarias en sentido general. 
Muchas han sido las definiciones que la doctrina ha expuesto sobre la figura del albacea, de ahí que autores como BorDA ${ }^{26}$ manifiesten que es la persona designada por el testador para hacer cumplir sus disposiciones de última voluntad, criterio amplio que no enmarca la figura del albacea a la sucesión testamentaria. Sin embargo, para otros autores como Difz PICAZO y GULLóN ${ }^{27}$ el albacea es la persona nombrada por el testador para ejecutar las disposiciones testamentarias, postura asumida por el legislador cubano al regular la figura en el capítulo dedicado a la ejecución del testamento, específicamente en el título II.

La naturaleza jurídica del albaceazgo ha suscitado también una larga controversia. Según la opinión más difundida, el albaceazgo es un mandato post mortem, de naturaleza especial. Para otros es un oficio, y algunos lo consideran una representación. No obstante, coincidimos con el criterio de Puig Brutau, quien dice que "el albaceazgo es puro y simplemente el albaceazgo; que no es asimilable al mandato, ni a la representación, ni a ninguna otra figura más o menos similar; que tiene su sustantividad propia y que debe fundarse en el reconocimiento de las siguientes cualidades que son inherentes a su naturaleza: 1) deriva su autoridad del testador; 2 ) tiene una posición independiente de los herederos; 3) sus actos producen efectos respecto de los bienes de la herencia y de quienes están interesados en ellos; 4) desplaza a los herederos en algunas de sus atribuciones; 5) terminada su gestión, debe dar cuenta a los herederos ${ }^{\prime 28}$. Nuestro Código Civil al respecto remite en su artículo 508 a las reglas relativas al mandato para regular las relaciones entre los herederos y el albacea.

El albaceazgo tiene los siguientes caracteres: es voluntario, tanto del punto de vista del testador como del albacea ${ }^{29}$; es personalísimo, no puede ser delegado, ni es posible sustituir el cargo, lo que es natural pues la designación importa un acto de confianza personal del causante; es gratuito; y es testamentario, tiene su origen en una designación contenida en el testamento. Particularmente sobre las facultades de los albaceas, a tenor de la legislación cubana, me estaré refiriendo con posterioridad.

26 BORDA (1994) p. 1120.

27 Diez y Gultón (1983) p. 544.

28 Puig Brutau, cit. pos. Borda (1994) p. 1628.

29 Art. 505.2 del Código Civil cubano. 


\section{La utilidad práctica del albacea en materia de disposiciones atípicas}

La utilidad de la institución es innegable pues no siempre son los herederos quienes ofrecen mejores garantías para cumplir legalmente la voluntad del causante. Los herederos y demás sucesores en aras de sus propios intereses pueden descuidar la ejecución del testamento. No obstante, existen criterios como el de ArIAS que consideran que el albacea en algunos casos puede ser perjudicial, si se encamina su función a la destrucción de papeles o cuestiones de la intimidad familiar ${ }^{30}$. En la doctrina, autores como GatTI ubican en tres grandes posiciones las posturas doctrinales sobre la utilidad del albacea. A decir de este autor, un primer grupo destaca de innegable la utilidad de la institución en varios supuestos como cuando existan ausencia de herederos en el testamento, o herederos menores, incapaces y ausentes, o ante la presencia de intereses contrapuestos de los herederos en relación al contenido del testamento y el carácter imparcial del albacea o porque el cumplimiento de la manifestación de última voluntad sea una carga gravosa para el heredero que no quiera o pueda realizar de forma espontánea. Un segundo grupo niega su utilidad al señalar que con la figura del albacea se genera un nuevo heredero. Y una tercera postura sostiene que la utilidad de la institución estará en dependencia de cada caso concreto y de los riesgos que puedan presentarse de que la voluntad del testador se quedare sin cumplir ${ }^{31}$.

Ciertamente compartimos el criterio de que cada caso concreto amerita una valoración diferente en torno a la utilidad del albaceazgo. Sin embargo, la práctica ha demostrado que hay situaciones jurídicas que hacen indiscutible la necesidad del albacea, nos referimos puntualmente a los casos en que toda la herencia está distribuida en legados ${ }^{32}$. Igualmente, con la existencia en el testamento de disposiciones extra-patrimoniales, de las cuales no podemos perder de vista su naturaleza y muchas veces la intención del testador al disponerlas. No en pocos casos este tipo de disposición responde a elementos muy subjetivos del testador, que no siempre implican un asentimiento por parte de los sucesores. Uno de los casos más controvertidos es el reconocimiento de la paternidad de un hijo, el consentimiento para la fecundación post mortem y hasta el reco-

30 ARIAS, cit. pos. COBAS (2007) p. 35.

31 Gatti, cit. pos. СовAs (2007) p. 35.

32 Sobre este particular, Vid. Dictamen $n^{\circ} 6$, de 2013. 
nocimiento de una deuda. Son declaraciones que pueden implicar un menoscabo para los herederos tanto en el plano patrimonial como en el afectivo, poniéndose en peligro su ejecución si no es confiada a alguna persona cercana al testador.

Con respecto a estas disposiciones pueden ocurrir varias cosas. En primer lugar, que coexistan con otras relativas al dispositivo patrimonial, no existiendo institución de herederos, distribuida toda la herencia en legados ¿Quién las ejecutaría?

En segundo lugar, puede el testamento sólo contener disposiciones no patrimoniales, criterio muy cuestionable que aún suscita debate, resultando interesante el criterio de PLANIOL y RIPERT, quienes han expresado que "los legados y las cargas patrimoniales constituyen las principales disposiciones testamentarias. Pero frecuentemente el testamento contiene disposiciones puramente extra-patrimoniales, previstas o no por la ley. Más aun, un testamento puede limitarse a disposiciones extra-patrimoniales, sin contener legado alguno" ${ }^{\prime \prime 3}$. Y en tercer lugar, aun existiendo herederos o sucesores instituidos exista la desconfianza del testador para la ejecución del testamento en lo referido a este tipo de disposición, que por su naturaleza puede implicar un interés contrapuesto a los de los herederos.

Con objetividad podemos afirmar que la no designación de albacea para ejecutar las disposiciones atípicas puede poner en riesgo la voluntad del testador, la cual no podrá ejecutar el notario pues no es heredero ni albacea, atentando este proceder contra el principio de imparcialidad, toda vez que es el funcionario autorizante del instrumento. En todo caso, sí deberá asesorar a los usuarios sobre las posibles consecuencias, haciendo uso de su labor propia.

\section{Problemáticas jurídicas que puede suscitar la ejecución de algunas disposiciones atípicas en Cuba}

Particularmente la ejecución de las disposiciones atípicas presenta una problemática que parte de la concepción patrimonialista del contenido

33 Planiol y Ripert (1935) p. 661. 
testamentario en nuestro país. El artículo 476 del Código Civil cubano, en un intento por definir ese acto jurídico mortis-causa, resulta de alcance limitado porque sólo lo reduce al contenido eminentemente patrimonial ${ }^{34}$. De ahí que los preceptos acogidos en el capítulo IV del libro cuarto, en sus artículos del 505 al 508 relativos al albaceazgo, sean reflejo de la citada noción del testamento que impuso el legislador cubano.

El artículo 506.1 permite colegir las amplias facultades que pueden tener los albaceas en correspondencia con el principio de autonomía de la voluntad del testador. No obstante, estas facultades no deben ser contrarias a las leyes. A tenor del precepto es posible que cumpliendo la voluntad del testador los albaceas cumplan facultades de índole no patrimonial, atípicas y anómalas ${ }^{35}$.

Sin embargo, el apartado 2 del artículo 506 establece las facultades del albacea para el caso en que el testador no las haya determinado, haciendo referencia exclusivamente a: representar a la herencia en juicio y fuera de él; conservar y administrar los bienes que integran la herencia; cobrar y pagar las deudas; y satisfacer los legados y cargas. Obviamente quedan restringidas las facultades del albacea en lo tocante a las disposiciones atípicas que bien pueden constituir parte del contenido testamentario. $\mathrm{Si}$

34 "(...) al ser el testamento un acto dispositivo de bienes o derechos para después de la muerte, no es válido como tal si no consta con claridad (...) la intención de testar, o lo que es lo mismo, de disponer para después de ocurrido el deceso del otorgante, de lo que se colige que con independencia de los términos y modo en que se expresa el testador sí es de obligada exigencia la presencia como esencia de la disposición mortis causa en sus frases (...)". Tribunal Supremo de Cuba, Sala de lo Civil y de lo Administrativo ( $n^{\circ} 83$ ).

35 En este sentido resulta interesante la clasificación de JORDANO sobre el contenido del testamento, estableciendo diferencias entre las declaraciones normales y típicas, y las declaraciones anómalas testamentarias, patrimoniales o no patrimoniales, de índole negocial, ya sean típicas o atípicas. Al tratar las normales o típicas hace alusión a las que él Ilama principales (institución de herederos, legados y carga modal) y a las accesorias e instrumentales (disposiciones sobre la administración de los bienes legados a menores, el testamento revocatorio de otro anterior, las disposiciones encomendando al arbitrio de tercero decisiones que permite la ley en tema de distribución de la herencia, la fijación del orden de pago de los legados, nombramiento de albaceas, delimitación de sus facultades, disposiciones sobre la colación o partición, etc.). Respecto a las declaraciones anómalas testamentarias patrimoniales o no, hace distinción entre las típicas (previstas por la ley; como la rehabilitación del indigno, las disposiciones sobre sufragios y funerales, las disposiciones sobre el propio cadáver) y las atípicas (no previstas por la ley; pone de ejemplo las disposiciones sobre la suerte de la correspondencia, sobre el derecho de autor, la designación testamentaria del tercero beneficiario del contrato de seguro de vida, entre otras). JORDANO BAREA, cit. pos. LACRUZ y BINDER (1953), p. 22 O. 
el testador ha designando un albacea, no confiriendo facultades expresas, las reguladas legalmente a tenor de nuestras normas no ofrecen la posibilidad de que sean legitimados para ejecutar otras de naturaleza extra-patrimonial.

Por su parte, el Código Civil español de igual forma en el artículo 901 establece que los albaceas tendrán todas las facultades que expresamente les haya conferido el testador y no sean contrarias a las leyes. En correspondencia con el precepto anterior, el legislador en su artículo 902 hace alusión a las facultades de los albaceas no habiéndolas determinado el testador, siendo más coherente cuando en el apartado 3 consigna la posibilidad amplia que podrán tener de vigilar la ejecución de todo lo ordenado en el testamento.

El Código Civil argentino en su artículo 2523 establece que las atribuciones del albacea designado en el testamento son las conferidas por el testador y, en defecto de ello, las que según las circunstancias son necesarias para lograr el cumplimiento de su voluntad. La ejecución de las disposiciones extra-patrimoniales puede llevarse a cabo por los albaceas, pues al igual que en el Código Civil español la facultad de éstos no está limitada. Como es evidente, el principio es que el causante puede otorgar al albacea todas las facultades que estime necesarias para el cumplimiento de su misión. Empero, él no podría atribuirle facultades que excedieran su cometido de ejecutor testamentario, o que lesionaran los legítimos derechos de los herederos. Por ello, habiendo herederos, las atribuciones del albacea deben interpretarse restrictivamente, convirtiéndolo en un mero supervisor de la voluntad del causante en muchos casos.

\section{A) LA EJECUCIÓN DEL RECONOCIMIENTO TESTAMENTARIO DE LA PATERNIDAD}

El reconocimiento de la paternidad como disposición testamentaria tiene sus particularidades con respecto a otras de igual naturaleza, pues específicamente respecto a su ejecución pueden presentarse en la praxis varias situaciones a las que puntualmente no referiremos. En primer lugar, es meritorio destacar que el reconocimiento de la filiación "es una manifestación de paternidad o maternidad formulado a través de la palabra o de la conducta (reconocimiento expreso o tácito)". Se puede considerar, a nuestro entender, que es establecido por los ordenamientos como un medio para atribuir a los hijos que nacen en determinadas circunstancias un estado de filiación. Es un acto jurídico personalísimo y en virtud 
de nuestras leyes no es posible realizarlo por la vía testamentaria, careciendo de eficacia post mortem al no poder ser directamente inscribible en el Registro del Estado Civil una vez ocurrido el deceso del testador.

En este sentido, si el causante hubiera designado albacea confiriéndole la facultad expresa de ejecutar el reconocimiento, obviamente en las actuales circunstancias legislativas ese reconocimiento sólo serviría como medio de prueba. Si bien nuestra normativa civil no prohíbe que tales declaraciones puedan invocarse en un testamento, hoy, a la luz del Derecho Civil cubano, los efectos del reconocimiento de un hijo quedan reducidos a ser un medio de prueba que pudiera ser aportado en un proceso de filiación, en virtud de La Ley de Procedimiento Civil, Administrativo, Laboral y Económica de Cuba en su artículo 294, plasmando en sí la eficacia de los documentos públicos, donde se encuadra el testamento notarial.

Algo muy delicado es el problema de las acciones por reconocimiento de filiación que, habiendo herederos, no cabe duda que sólo ellos son parte en el juicio. Por tanto, los albaceas no estarían legitimados para iniciar estos procesos, convirtiéndose en meros vigilantes de la ejecución de estas acciones. Nuestra normativa en materia de relaciones familiares sólo legitima para reclamar el reconocimiento de los hijos a éstos y al padre o madre que ya los haya reconocido, con respecto al que aún no lo haya hecho ${ }^{36}$. No obstante, nada consigna respecto a la legitimación de los herederos del causante o familiares más próximos. La razón de tal olvido quizás obedezca a que por lo general a los herederos del causante no tendría por qué interesarles ese reconocimiento tardío que pudiera desfavorecerlos en la sucesión. Empero, la voluntad del testador y los intereses patrimoniales y afectivos del pretenso reconocido es razón suficiente para que una vez reformada la Ley $\mathrm{n}^{0} 1289$, de 1975, sean también legitimados otras personas que, a decir de Pérez Gallardo ${ }^{37}$, pudieran ser los más propincuos parientes del titular, que no los herederos, pues nada tiene que ver un heredero voluntario, no vinculado parentalmente con el titular de estas acciones, en su ejercicio, criterio que compartimos.

36 Así queda consignado en el artículo 77 del Código de Familia, aunque el Anteproyecto de Modificación de este Código en su versión de 2010 se proyecta en permitir que la acción de reclamación también puedan ejercitarla, en caso de fallecimiento del hijo o hija, sus herederos. PéreZ (2010) pp. 63-100. 
En el supuesto de no designar el testador a una persona específica para la ejecución de sus disposiciones mortis causa (atípicas o extra-patrimoniales), la ejecución corresponde a los propios herederos, al ser éstos los que presuntamente tienen mayor interés en el cumplimiento de la voluntad del causante. Sin embargo, tratándose del reconocimiento de un hijo en una cláusula testamentaria, como hemos planteado, pudieran sentirse afectados los herederos y no ejecutar la verdadera voluntad del testador, anteponiéndose a sus intereses. Si bien no podemos hablar de una eficacia post mortem del reconocimiento filiatorio en sede testamentaria, la subjetividad de los herederos puede sin lugar a dudas marcar una brecha irrealizable de la verdadera voluntad del testador.

Dado que el reconocimiento de la filiación repercute en el estado civil del individuo, constituye una cuestión relevante a la que el Derecho no debería dar la espalda. Es por ello que la vía testamentaria para el reconocimiento debe ser acogida en nuestro ordenamiento jurídico. Siendo así, si se tratase de un hijo mayor de edad y el albacea tuviera facultad expresa de ejecutar esta cláusula, debería poner en conocimiento al presunto hijo teniendo en cuenta que éste pudiera no tener conocimiento de la existencia del testamento en que se le reconoce el vínculo filial paterno o materno, por tanto se impondría en el momento de la aceptación y adjudicación de la herencia la necesidad de su participación a los efectos de consentir o no el reconocimiento, el que deberá ser requerido por el notario actuante.

Si se tratara del reconocimiento testamentario de un menor de edad para la ejecución de esa disposición, el albacea o ejecutor testamentario ineludiblemente deberá contar con el consentimiento del otro progenitor porque se pretende proteger las garantías concedidas por el legislador al que previamente lo reconoció, y para que éstas no queden burladas, su declaración debe ser considerada a tales efectos. En igual forma resultaría necesaria la intervención del Fiscal, en virtud de que diversos elementos subjetivos pudieran vincularse al beneplácito del progenitor ,y si bien no son cuestiones que atañen al Derecho, es necesario el establecimiento de garantías jurídicas que aseguren los derechos e intereses del menor, por encima de cualquier otro interés. Para la ejecución de este tipo de disposición es indispensable la presencia del Fiscal, pues al margen de la aquiescencia o no del progenitor que previamente había reconocido puede estar la mala fe del albacea, o simplemente el irrespeto 
de la voluntad del causante una vez que el ejecutor y los herederos de mutuo acuerdo pongan en peligro la verdadera voluntad del testador y los intereses del menor. Para ello esta problemática pudiera ser resuelta en virtud de que el notario a la luz del Reglamento de la Ley de las Notarías Estatales, artículo 168, inciso e, donde le es regulada la posibilidad de dar parte a las oficinas públicas de aquellos asuntos en los que fuera necesaria su intervención. Así, en el momento de la aceptación y adjudicación de la herencia, el notario debería emitir un parte a la Fiscalía poniendo en conocimiento el asunto, teniendo en cuenta los intereses del menor que pudieran ser lesionados.

\section{B) LA EJECUCIÓN DE LAS DISPOSICIONES TESTAMENTARIAS RELATIVAS A LA DACIÓN DE ÓRGANOS Y TEJIDOS}

Restablecer la salud de una persona a partir de implantes de órganos y tejidos partes de otra persona ha sido anhelo de la humanidad durante mucho tiempo. Afortunadamente los avances científicos han logrado descubrir los medios adecuados que reducen el peligro del rechazo y los trasplantes se han visto multiplicados. El trasplante implica la extracción de un órgano, tejido o célula de una parte del cuerpo de un individuo y su transferencia al cuerpo de otro, con el fin de restablecer la salud de este último. Esta operación, sin embargo, no se limita a aspectos técnicos o médicos, ya que en ella van implícitas consecuencias científicas, sociológicas, psicológicas, filosóficas y, desde luego, jurídicas.

Los avances de la medicina en Cuba sin duda dejarán atrás a abogados, notarios y juristas, en sentido general, que no reconozcan que el mundo ha sufrido enormes cambios. ¿Qué notario hubiera pensado que su noción de la propiedad, de la unidad de la persona, de las partes como integrantes de un todo, cambiaría de repente, para darse cuenta que al cuerpo humano se le puede incorporar sustancias y elementos, incluyendo órganos de otras personas y hasta provenientes de cadáveres?

La Ley de Salud Pública de Cuba, Ley no $41 / 1983$, de 13 de julio, en la Sección oncena del Capítulo II, dedicado a la atención médica y social, acoge en los preceptos 41 y 42 aspectos relacionados con las donaciones de órganos, sangre y otros tejidos. Sin embargo, estos artículos solamente remiten a las reglamentaciones del propio Ministerio de Salud, algunas de las cuales adquirieron forma por conducto del Reglamento de la Ley de Salud Pública, contenido en el Decreto n 139, de 1988, que a partir 
del capítulo IV, específicamente desde el artículo 80 hasta el 85, regula algunas de estas cuestiones. De la lectura e interpretación de los artículos del 83 al 85, cabe colegir que la modalidad de donación de órganos y tejidos humanos post mortem en Cuba es admitida, pues se supedita este proceder quirúrgico-terapéutico a la expedición del certificado médico de defunción ${ }^{38}$. De hecho, sólo hasta la promulgación de la Resolución $\mathrm{n}^{\circ}$ 857, de 2015, del 31 de agosto, del Ministro de Salud Pública ${ }^{39}$, era la única modalidad regulada, cuando a partir de esta normativa se comienza a admitir el trasplante de órganos provenientes de dadores vivos.

La donación de órganos y tejidos para después de la muerte es tratada legislativamente de forma distinta a la donación en vida, ya que no se intenta proteger la integridad física de un donante que ha dejado de existir, pues muerto el donante desaparece el gran obstáculo de la integridad física, entendida ésta en función del bien de la vida y de la persona. En estos casos, las exigencias versan sobre la comprobación previa a la extracción de los órganos y tejidos de la pérdida de la vida del donante y, por supuesto, del consentimiento expreso del disponente.

La donación post mortem presenta dificultades pues la persona dejó de ser al morir y su voluntad no puede expresarse. No obstante, su voluntad pudo haber sido expresada antes de su muerte, en el sentido de aceptar en vida que a su muerte sus componentes pudieran ser susceptibles de trasplantes o bien, por el contrario, negarse a ser donador. En nuestro país la manifestación de voluntad para la donación de órganos, consignada en el documento de identidad de las personas, fue una experiencia por años, pero con deficiencias prácticas. Sin embargo, se le atribuía la ventaja de que el donante siempre llevaba la tarjeta consigo, y se evitaba la innecesaria consulta a los familiares o la búsqueda de algún documento que acreditara esta voluntad.

En la actualidad, la declaración de voluntad para la donación de órganos se realiza tanto en instrumentos notariales como ante autoridades judiciales, registrales o administrativas, en dependencia de cada país. Tam-

38 Decreto ${ }^{\circ}{ }_{139}$, de 1988. El artículo 83 deja explícito que: "Todo proceder médico en la realización de trasplantes de órganos y tejidos donados estará condicionado a la certificación de la muerte del donante".

39 Gaceta Oficial de la República de Cuba, extraordinaria, $n^{\circ} 33$, de 2015. A los efectos de profundizar en el tema, Vid. Pérez (2015). 
bién el testamento es un instrumento jurídico que puede se reservorio de manifestaciones de esta naturaleza, pero en la práctica esa clase de donación no es muy segura, ya que las provisiones testamentarias rara vez se notifican a tiempo para permitir que la donación de órganos se realice oportunamente.

La disposición testamentaria de donación de órganos para después de la muerte, que debe ser expresa, es un acto unilateral que surte efectos a la muerte del testador y es revocable por el propio disponente, pero no por terceros, por ejemplo familiares. El testador en su testamento puede especificar qué órganos u órgano son materia de donación y quiénes son las personas beneficiadas con la donación. En nuestro país no es usual, en la práctica notarial, encontrar en testamentos disposiciones sobre donación de órganos y tejidos, quizás por la insuficiente información sobre la forma en que operan estas disposiciones.

Este tipo de manifestación plantea un primer problema y es que los testamentos suelen leerse una vez que la persona ha fallecido, que es cuando comienzan a desplegarse los efectos jurídicos del acto. El contenido de las cláusulas testamentarias puede conocerse inmediatamente al ocurrir el deceso del testador, pero pueden pasar días y meses para su apertura, y en estos supuestos, los órganos y tejidos del cuerpo humano poseen un estadio muy breve de vida, que no pueden quedar al margen del conocimiento de este tipo de disposición. El artículo 42 de la Ley de Salud Pública de Cuba, Ley $n^{\circ} 41$, de 1983, consigna las distintas etapas por las cuales debe transitar el proceso de donación que se inicia a partir de la conservación inmediata del tejido en buen estado, el cual descansa totalmente en el personal médico vinculado a esta actividad y que puede requerir procedimientos especiales. Luego se procura la conservación, que es la permanencia de las características vitales y efectivas del tejido u órgano por tiempo determinado o no, en tanto aparezca la posibilidad de utilizar el mismo en otra persona.

En este caso ha de jugar un papel esencial la labor asesora del notario, quien oportunamente deberá aconsejar al testador de que para lograr la eficacia de estas disposiciones resultaría de suma importancia darlas a conocer a los albaceas o herederos antes de su fallecimiento, obviamente evitando que el tiempo entre la muerte del testador y la lectura del contenido del testamento imposibilite cumplir la voluntad manifiesta 
del causante, aunque infaliblemente este proceder pudiera atentar contra la secretividad del testamento. Lo cierto es que la vía testamentaria para emitir esta voluntad puede ser en muchos casos ineficaz por los argumentos antes esgrimidos, sin embargo, en virtud del principio de autonomía de la voluntad, nada impide que sea una manifestación que los usuarios quieran plasmar en sus testamentos. Al margen de otras vías que puedan articularse en el ordenamiento jurídico cubano para emitir el consentimiento para la donación de órganos y tejidos, siempre el testamento podrá ser una alternativa, aun con las disyuntivas expuestas.

\section{C) LAS DISPOSICIONES RELATIVAS AL DESTINO DEL CADÁVER Y LOS RESTOS} MORTALES. SU EJECUCIÓN

Al igual que el sistema normativo reconoce a los hombres el derecho a disponer post mortem sobre sus bienes, de la misma forma puede y debe atender a esa misma voluntad y libertad permitiéndole disponer sobre el destino de sus restos mortales. Desde siempre el hombre ha visto en los cadáveres la manifestación más cercana del misterio de la muerte. Por ello existe una natural inclinación humana a darle consideración especial a los cadáveres y hasta tipificar como actos delictivos los relativos a su profanación.

Estas disposiciones que pueden hacerse en testamento no tienen una regulación o reconocimiento expreso en nuestras normas. Sin embargo, son válidas y en la práctica notarial se encuentran esta clase de disposiciones testamentarias relativas al cadáver del testador, sus restos mortales y a su funeral.

Hay autores que establecen que para que tenga una eficacia jurídica plena es necesario que se establezca como una carga a determinado legatario o heredero, bajo apercibimiento de que si no la cumple se resuelva su nombramiento, dejando de ser heredero o legatario. Por lo general, el incumplimiento de esta disposición no tiene consecuencias para los obligados moralmente a cumplirlas. Actualmente las disposiciones testamentarias de esta naturaleza suelen señalar que el cadáver sea enterrado, cremado o no cremado y algunas añaden el destino que el testador desea tengan las cenizas. Al parecer estas cuestiones resultan sencillas para el Derecho. Sin embargo, en no pocas ocasiones pueden volverse un conflicto al ser situaciones de gran coste personal para los implicados y de difícil arreglo pacífico entre los miembros de la familia. 
En Cuba se está produciendo un avance de la cremación en relación con el tradicional rito de la inhumación, lo que se explica por diversas razones, desde la evolución del sentimiento religioso a motivos puramente económicos, y ello extiende los posibles conflictos no sólo ya al momento del enterramiento, que era lo habitual, sino a la posterior custodia y destino de los restos mortales. Pese a ello, nuestra legislación no proporciona respuestas claras sobre esta materia. Hay una auténtica laguna legal que deberá ser salvada en principio por los notarios con su labor de asesoramiento, pues como hemos reiterado, para estos asuntos la designación de albacea pudiera ser un cauce eficaz que impida posibles conflictos entre herederos y permita la ejecución de la voluntad del causante, siempre y cuando en el testamento se le confiera la facultad expresa pues hoy, en virtud de nuestra legislación civil, las facultades legales de los albaceas no hacen alusión a éstas de singular naturaleza.

Aunque esta facultad se puede decir que normalmente pudiera no ser efectiva, ya que el sepelio, como las honras fúnebres más importantes tienen lugar tan inmediatamente después del fallecimiento, no es corriente ni que aún se conozca el testamento, y quién es el albacea. Esa inefectividad, que es por demás clara, la pone también de relieve la doctrina. Aunque al respecto SÁNCHEZ Román ha expresado que "sería lícita su intervención en las disposiciones necesarias para el mismo cuando fuere conocido en aquellos primeros momentos su carácter de albaceas, no obstante el respeto debido a la voluntad de la familia y a las iniciativas que generalmente toman o concurso que prestan las personas amigas que la rodean en tan tristes circunstancias" ${ }^{\prime \prime}$.

En el artículo 902.1, el legislador español al regular las facultades legales de los albaceas refiere la de disponer y pagar los sufragios del testador con arreglo a lo dispuesto por él en el testamento, y en su defecto según la costumbre del pueblo. La legislación civil cubana es omisa sobre tales facultades, siendo común en la práctica social cubana que sean los familiares y amigos más allegados del causante quienes ejecuten estas disposiciones, pero nada quita que conociéndose con anterioridad a la muerte del testador quién ha de ostentar la función de albacea, éste bajo tal envestidura realice las operaciones relacionadas con el funeral, entierro o cremación del causante, incluso con sus fondos propios, el cual sin dudas

40 SánChez (1910) p. 207. 
deberán ser reembolsados por los herederos, conforme al artículo 405, inciso b del Código Civil cubano, que regula lo concerniente al mandato, en virtud del artículo 508, que remite a tales preceptos.

En cuanto a las disposiciones que ha de adoptar el albacea sobre todo lo anterior, no es libre de atenerse simplemente a lo que él prefiera, sino que, de haber establecido algo el testador en su testamento, debe acatarlo y, en su defecto, atenerse, por supuesto, a las creencias del difunto si profesaba alguna religión.

\section{CONCLUSIONES}

En nuestro sistema jurídico se hace cada vez más necesario el perfeccionamiento de las normas jurídicas civiles y familiares, retomando además algunas figuras que en el ámbito histórico y comparado resultan de indudable trascendencia a los efectos de hacer menos engorrosa y difícil la aplicación del Derecho. En particular, el tratamiento brindado a la definición de testamento en la legislación civil cubana adolece en gran medida de un exiguo rigor científico. Más que brindar una definición del instituto, encamina el precepto a la regulación del contenido que puede albergar un testamento, resultando así limitado pues sólo lo reduce al contenido eminentemente patrimonial, quedando excluidas las disposiciones no patrimoniales que bien pueden formar parte única del contenido de un testamento. En consecuencia, los preceptos relacionados con la sucesión testamentaria responden a la concepción patrimonialista del Código Civil cubano. Igualmente figuras como el albaceazgo no cuentan con una regulación adecuada que permita dar solución a la gran gama de dilemas socio-jurídicos que hoy se visualizan, dado que no se puede perder de vista la utilidad innegable de la institución, ya que no siempre son los herederos quienes ofrecen mejores garantías para cumplir legalmente la voluntad del causante. En aras de sus propios intereses, los herederos y demás sucesores pueden descuidar la ejecución del testamento, especialmente de aquellas disposiciones atípicas testamentarias que poseen características especiales. El Derecho en Cuba, sin dudas, deberá abrir los horizontes que permitan desplegar todo el acervo cultural que hoy va ganando el ciudadano cubano. 


\section{BIBLIOGRAFÍA CITADA}

Borda, Guillermo (1994): Tratado de Derecho Civil, Sucesiones, Tomo II (Santiago, Editorial Abeledo-Perrot).

CASTÁn, José (1952): Derecho Civil Español, Civil y Foral, Tomo I, Volumen II (8 ${ }^{a}$ Edición, Reus).

_- (1989): Derecho Civil Español, Común y Foral (8ª Edición, Madrid, Reus, Volumen $\left.\mathrm{VI}-1^{\circ}\right)$.

СовAS, María (2007): El Albaceazgo (Cizur Menor, Editorial Aranzadi).

Diez, Luis y Gultón, Antonio (1983): Sistema de Derecho Civil, Volumen IV,

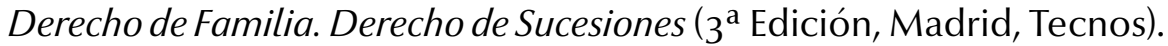

ENNECCRUS, Ludwig, KIPP, Theodor y Wolff, Martin (1951): Tratado de Derecho Civil, Tomo V-1, Derecho de Sucesiones (Trad. por la $8^{\text {a }}$ revisión alemana por Blas Pérez González y José Alguer, adaptado a la legislación y jurisprudencia españolas por Ramón María Roca SASTRE. Bosch, Barcelona) (Barcelona, Editorial Bosch).

LACRUZ, José y BINDER, Julio (1953): Derecho de Sucesiones (Barcelona, Editorial Laber).

López, Nicholás (1916): Tratado Teórico Legal de Derecho de Sucesión. Tomo

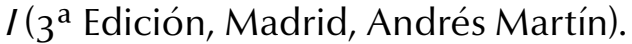

Pérez, Leonardo (2004): Derecho de Sucesiones, Tomo I (La Habana, Félix Varela).

- (2010): "Luces y Sombras en torno a la regulación jurídica de la filiación en Cuba", en Sánchez, José, Gardeazábal, Francisco; Garrido, Pedro (coord.), Homenaje a Víctor Manuel Garrido de Palma. Revista Derecho y Humanidades, $\mathrm{n}^{\mathrm{O}} 16$, vol. 2.

- (2015): "Dación de órganos y tejidos humanos entre vivos y función notarial", Revista IUS, Vol. 9, no 36 . 
Planiol, Marcelo y RiPeRT, Jorge (1935): Tratado Práctico de Derecho Civil Francés, Tomo V (Trad. por Mario Díaz Cruz) (La Habana, Colegio de Abogados de La Habana).

Rivas, José (2005): Derecho de Sucesiones. Común y Foral. Tomo I ( $3^{\text {a Edi- }}$ ción, Madrid, Dykson).

Rotond, Mario (1953): Sucesión Testamentaria (Barcelona, Laber).

SÁnCHEZ, Felipe (1910): Estudios de Derecho Civil, Tomo VI, Volumen I ( $2^{\mathrm{a}}$ Edición, Madrid, Editorial Sucesores de Rivadeneira).

Valverde, Calixto (1939): Tratado de Derecho Civil Español, Tomo V (4 ${ }^{\mathrm{a}}$ Edición, Valladolid, Editorial Cuesta).

\section{NORMAS JURÍDICAS CITADAS}

Código Civil de España, del 6 de octubre de 1888.

Código Civil de la República de Argentina, del 25 de septiembre de 1869.

Código Civil de la República de Colombia, del 26 de mayo de 1873 y puesto en vigor por Ley $\mathrm{n}^{\circ} 57$ de 1887.

Código Civil de la República de Cuba, Ley n 59, del 16 de julio de 1987.

Código de Familia de la República de Cuba, Ley n 1289, de 1975, vigente desde el 8 de marzo de 1975.

Decreto $n^{\circ} 139$ del 4 de febrero de 1988, que establece el Reglamento de la Ley de Salud Pública.

Dictamen $n^{\circ}$ 6, de 2013, de la Dirección Nacional de Registros y Notarías de Cuba.

Ley de Salud Pública de Cuba, Ley no 41, del 13 de julio de 1983. 
Ley $\mathrm{n}^{\circ}$ 50, Ley de las Notarías Estatales, del 28 de diciembre de 1984.

Resolución no 857, del 31 de agosto de 2015, del Ministro de Salud Pública. Disponible en la Gaceta Oficial de la República de Cuba, extraordinaria, $\mathrm{n}^{\mathrm{O}} 33$, de 2015 . 